\title{
HBA1C AND MICROCYTIC ANAEMIA, IS THERE A LINK?
}

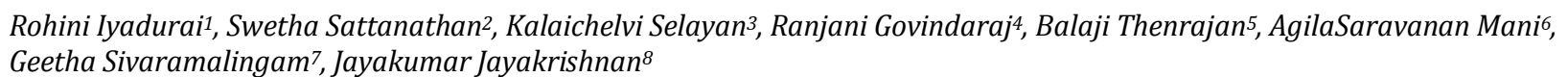

${ }^{1}$ Assistant Professor, Department of Medicine, Government Royapettah Hospital.
2Junior Resident, Department of Medicine, Government Royapettah Hospital.
${ }^{3}$ Assistant Professor, Department of Medicine, Government Royapettah Hospital.
${ }^{4}$ Assistant Professor, Department of Medicine, Government Royapettah Hospital.
${ }^{5}$ Assistant Professor, Department of Medicine, Government Royapettah Hospital.
${ }^{6}$ Assistant Professor, Department of Medicine, Government Royapettah Hospital.
${ }^{7}$ Assistant Professor, Department of Medicine, Government Royapettah Hospital.
${ }^{8}$ Assistant Professor, Department of Medicine, Government Royapettah Hospital.

ABSTRACT

Protein glycation is a spontaneous reaction that happens as a function of the circulating blood sugar levels. The major form of protein glycation with a clinical consideration is glycated haemoglobin (HbA1c). The HbA1c fraction being abnormally elevated in chronic hyperglycaemic diabetic patients is used as a marker of glycaemic control. However, altered HbA1c levels have been documented in anaemic patients without any history of diabetes and the reports on the effects of iron deficiency an aemia on HbA1c levels are inconsistent. This study was henceforth conducted to establish the effect of microcytic hypochromic anaemia on HbA1c levels in non-diabetic individuals.

\section{AIM}

The aim of this study was to determine the effect of microcytic anaemia on the HbA1c levels in non-diabetic patients, so as to consider anaemia as an important factor which influences the HbA1c levels while monitoring the glycaemic status of diabetics.

\section{METHODOLOGY}

Fifty non-diabetic, anaemic patients and 50 age-matched healthy subjects were enrolled in this study. The patients who had glucose tolerance abnormalities (Impaired glucose tolerance or diabetes mellitus), haemoglobinopathies, haemolytic anaemia, infestation, chronic alcohol ingestion and chronic renal failure were excluded from the study. Haematologic investigations were done and the fasting and postprandial glucose and HbA1c levels were measured in all the subjects.

\section{RESULTS}

The mean HbA1c $(5.32 \pm 0.3 \%)$ level in the patients with IDA was higher than that in the control group $(5.14 \% \pm 0.5)(p<0.05)$. There were no differences in the levels of fasting and postprandial glucose between the IDA and the control groups ( $p>0.05$ ). The haemoglobin, fasting and postprandial glucose and the HbA1c levels were normal in the control group ( $p>0.05)$.

\section{CONCLUSION}

HbA1c is not affected by the blood sugar levels alone, and there are various confounding factors when HbA1c is measured, especially that of microcytic anaemia, probably due to iron deficiency which is very common in this part of the world. It is hence prudent to rule out anaemia, especially microcytic anaemia before making a therapeutic decision based on the HbA1c levels.

\section{KEYWORDS}

Microcytic Anaemia, Haemoglobin A1c, HbA1c, Glycated Haemoglobin, Diabetes.

HOW TO CITE THIS ARTICLE: Iyadurai R, Sattanathan S, Selayan K, et al. HBA1C and microcytic anaemia, is there a link?. J. Evolution Med. Dent. Sci. 2016;5(54):3624-3628, DOI: 10.14260/jemds/2016/835

\section{INTRODUCTION}

Diabetes mellitus, a disorder of chronic hyperglycaemia is caused by either deficient production or inefficient utilization of insulin. According to World Health Organization (WHO), Diabetes will be the 7th leading cause of mortality by 2030.1 India with around 62 million people diabetics is rightly named "the diabetes capital of the world" by Indian Heart Association. ${ }^{2}$ Hence, a great amount of enthusiasm has been

Financial or Other, Competing Interest: None.

Submission 02-06-2016, Peer Review 25-06-2016,

Acceptance 02-07-2016, Published 07-07-2016.

Corresponding Author:

Rohini Iyadurai,

3/634, Jaganathan Street,

Kottivakkam

Chennai-41.

E-mail:ro9567@yahoo.in

DOI: $10.14260 /$ jemds/2016/835 involved in easing the diagnosis and monitoring of diabetes. HbA1c (Glycated haemoglobin) is one such entity, which has secured a pivotal place in the diagnostic criteria for diabetes. It was introduced as a marker of the glycaemic control status over the past 2-3 months and has come a long way in being used as a diagnostic modality for diabetes approved by the World Health Organisation (WHO) and American Diabetes Association (ADA). The recent identification of various pitfalls and confounding factors in the measurement of $\mathrm{HbA1c}$ has necessitated the review of its role. It is advised to be used with caution in certain population groups such as children, pregnant women, patients with haemolytic anaemia or haemoglobinopathies. One such confounding factor has been identified as anaemia and the iron stores (ferritin) of the individual. ${ }^{3}$ The exact role of anaemia on $\mathrm{HbA} 1 \mathrm{c}$ estimation is yet to be established as the studies conducted so far have given conflicting results. This study has been henceforth 
conducted to establish the effect of microcytic hypochromic anaemia on HbA1c levels if any.

\section{METHODOLOGY AND DATA COLLECTION}

A detailed history regarding age, sex, occupation, diet, menorrhagia and anthropometrical measurements made. After obtaining their consent, blood was drawn and the following parameters done:

- Haemoglobin Levels (Hb):

- Mean Corpuscular Volume (MCV):

- Mean Corpuscular Haemoglobin (MCH):

- Mean Corpuscular Haemoglobin Concentration (MCHC):

- Red Cell Distribution Width (RDW):

- Platelets:

- Erythrocytes:

- White Blood Cell Count:

- Serum Fasting and Postprandial Glucose Levels: Serum Creatinine:

- HBA1C:

- Absolute HBA1C: Glycated Haemoglobin (\%)* haemoglobin (g/dL)/100 Laboratory Methods:

Evaluation of the Haemogram was done using Sysmex automated cytology analyser. HbA1c was analysed using High Performance Liquid Chromatography (HPLC). Blood glucose estimation was done using glucose oxidase method. Serum creatinine was estimated using Jaffe's kinetic method.

\section{Definitions. ${ }^{4,5}$}

Microcytic hypochromic anaemia was defined as Haemoglobin less than $13 \mathrm{~g} / \mathrm{dL}$ in males; less than $12 \mathrm{~g} / \mathrm{dL}$ in females; RBC count less than 4,50,000 in males; less than $3,50,000$ in females; Mean Corpuscular Haemoglobin (MCH) less than 27 pg. and Mean Corpuscular Haemoglobin Concentration (MCHC) less than $33 \mathrm{~g} / \mathrm{dL}$ and Mean Corpuscular Volume (MCV) less than $76 \mathrm{fL}$ having microcytic hypochromic anaemia in peripheral smear study. Healthy controls were defined as non-anaemic population with normal red cell indices and normal peripheral smear study.

\section{Statistical Analysis}

The results obtained were analysed using SSPS software. T-test was applied in comparative analysis results between different groups and to find significant (P) value. Mean values, Standard Deviation (S.D.), prevalence was assessed wherever relevant.

\section{RESULTS}

For all practical purposes, anaemia defined in the analysis and future discussion is to be considered as microcytic hypochromic anaemia as defined above.

Of the 100 participants, $63 \%$ (27 cases and 36 controls) are in the age group of $12-20$ years, $20 \%$ (13 cases and 7 controls) in the age group of $21-40$ years, $12 \%$ (7 cases and 5 controls) in 41-60 years' age group and 5\% (3 cases and 2 controls) above 60 years. The majority of the anaemic (27\%) were in the 12-20 years' age group and least in the group above 60 years.

There were 76 females and 24 males in the study population. Out of the 24 male participants $10(41.7 \%)$ were anaemic and out of the 76 female participants 40 (52.6) were anaemic. The increased number of female participants can be explained by the increased prevalence of anaemia among women due to various reasons; 10 male anaemic patients make up $20.0 \%$ of the total anaemic population, while 40 female anaemic patients make up the rest.

No stratification of severity of anaemia was attempted. Hence, the prevalence of severe anaemia could not be studied.

Majority of the participants of the study are students (63\%). Out of these 63 students, 29 (46\%) had anaemia. The next major group involved was employed people $(27 \%)$ with $14(51.9 \%)$ being anaemic. The anaemic patients of these two groups constitute a total of $43(86 \%)$ cases of anaemic patients in the study. These two groups having a higher percentage of anaemia reflect the burden of anaemia on the work force of the society.

Only $25(53.2 \%)$ of the 47 women with menorrhagia had anaemia, while the rest $22(46.8 \%)$ are healthy. But out of 29 participants who did not have menorrhagia, 15 (51.7\%) are anaemic. The association between menorrhagia and anaemia was not statistically significant.

Out of the 87 non-vegetarians $42(48.3 \%)$ were anaemic, while $45(51.7 \%)$ were non-anaemic. Out of the 13 vegetarians, $8(61.5 \%)$ were anaemic. The association between diet habits and anaemia was not statistically significant.

The mean BMI in the anaemic population was 19.91 with S.D. 3.7, while it was 22.51 with S.D. 3.0 in healthy controls. The lower mean BMI in the anaemic group can be explained, as the patients had moderate-to-severe anaemia $(<10 \mathrm{~g} \% \mathrm{Hb})$ and the cause and effect of anaemia on BMI could be taken as the probable explanation.

The mean Red Blood Corpuscles (RBC) count in anaemic population was: male -3.01 million $/ \mathrm{mm}^{3}$ and female -2.81 million $/ \mathrm{mm}^{3}$.

The mean Red Blood Corpuscles (RBC) count in healthy male and female population were 4.75 million $/ \mathrm{mm}^{3} 4.03$ million $/ \mathrm{mm}^{3}$.

The mean value of $\mathrm{Hb}$ in anaemic male and female population were $7.72 \mathrm{~g} / \mathrm{dL}$ and $7.26 \mathrm{~g} / \mathrm{dL}$ respectively, while the mean value of $\mathrm{Hb}$ in healthy male and female population were $14.21 \mathrm{~g} / \mathrm{dL}$ and $13.51 \mathrm{~g} / \mathrm{dL}$ respectively. The mean value of $\mathrm{Hb}$ in anaemic population was lower when compared to the mean $\mathrm{Hb}$ values in the study of Shanthi et al, which was conducted in the same city representing a similar population.

The possible explanations include involving people from lower socioeconomic status and the study population involving Inpatients who are probably severely anaemic.

The mean value of Mean Corpuscular Volume (MCV) in anaemic population was $69.92 \mathrm{fL}$ and in healthy population it was $91.20 \mathrm{fL}$

The mean value of Mean Corpuscular Haemoglobin (MCH) in anaemic population was $26.7 \mathrm{pg}$ and in healthy population was $30.5 \mathrm{pg}$.

The mean value of Mean Corpuscular Haemoglobin concentration (MCHC) in anaemic population was $33.5 \mathrm{~g} / \mathrm{dL}$ and in healthy population it was $38.5 \mathrm{~g} / \mathrm{dL}$.

The mean value of Red Cell Distribution width (RDW) in anaemic population was 19.65 and in healthy population it was 13.21.

The difference in MCV, MCH, MCHC and RDW between the groups were statistically significant $(\mathrm{P}<0.001)$

The mean platelets count in anaemic population was 3.22 
lakhs $/ \mathrm{mm}^{3}$, which was not statistically significant from that of the mean platelets of 2.95 lakhs $/ \mathrm{mm}^{3}$ in healthy population.

The mean White Blood Cell (WBC) count in anaemic population of 6,950 cells $/ \mathrm{mm}^{3}$ and was not differing significantly from that of the healthy population's value of 6,796 cells $/ \mathrm{mm}^{3}$.

The mean fasting blood sugar in the anaemic population was $78.72 \mathrm{mg} / \mathrm{dL}$ and healthy population was $81.14 \mathrm{mg} / \mathrm{dL}$. $(\mathrm{P}>0.05)$.

The mean post-prandial blood sugar in the anaemic population was $124.68 \mathrm{mg} / \mathrm{dL}$ and the healthy population was $126.32 \mathrm{mg} / \mathrm{dL}$. $(\mathrm{P}>0.05)$.

The mean $\mathrm{HbA} 1 \mathrm{c}$ in anaemic population was $5.32 \% \pm 0.32$, while the mean $\mathrm{HbA1c}$ in healthy non-anaemic population was $5.14 \% \pm 0.53$. There was a statistically significant difference between two mean values at $P$ value of 0.04 .

The mean absolute $\mathrm{HbA1c}$ in anaemic population was $0.63 \pm 0.0$, while the mean absolute $\mathrm{HbA1c}$ in healthy nonanaemic population was $0.70 \pm 0.07$. The difference was not statistically significant $(\mathrm{p}>0.05)$.

\begin{tabular}{|c|c|c|c|c|}
\hline & \multicolumn{2}{|c|}{ Anaemia } & & \\
\hline & & & Total & P Value \\
\hline & Anaemic & Healthy & & \\
\hline $12-20$ & 27 & 36 & 63 & \\
\hline & $(42.9 \%)$ & $(57.1 \%)$ & $(63 \%)$ & \\
\hline $21-40$ & 13 & 7 & 20 & \\
\hline & $(65 \%)$ & $(35 \%)$ & $(20 \%)$ & \\
\hline & & & & $\geq 0.05$ \\
\hline $41-60$ & 7 & 5 & 12 & \\
\hline & $(58.3 \%)$ & $(41.7 \%)$ & $(12 \%)$ & \\
\hline & 3 & & & \\
\hline Above 60 & $(60 \%)$ & $(40 \%)$ & $(5 \%)$ & \\
\hline \multicolumn{6}{|c|}{} & & 2 & 5 & \\
\hline \multicolumn{6}{|c|}{ Table 1: Age Wise Distribution of Participants } \\
\hline
\end{tabular}

\begin{tabular}{|c|c|c|c|}
\hline Sex & Anaemic & Healthy & Total \\
\hline \multirow{2}{*}{ Male } & 10 & 14 & 24 \\
& $(41.7 \%)$ & $(58.3 \%)$ & $(24 \%)$ \\
\hline \multirow{2}{*}{ Female } & 40 & 36 & 76 \\
& $(52.6 \%)$ & $(47.4 \%)$ & $(76 \%)$ \\
\hline \multicolumn{3}{|c|}{ Table 2: Sex Distribution and } \\
Microcytic Hypochromic Anaemia
\end{tabular}

\begin{tabular}{|c|c|c|c|}
\hline & Anaemia & Mean \pm S.D. & P value \\
\hline \multirow[t]{2}{*}{ BMI } & Anaemic & $19.91 \pm 3.7$ & $<0.001$ \\
\hline & Healthy & $22.51 \pm 3.0$ & \\
\hline \multicolumn{4}{|c|}{ Table 3: BMI and Anaemia } \\
\hline
\end{tabular}

\begin{tabular}{|c|c|c|c|c|}
\hline \multirow{4}{*}{ Sex } & \multicolumn{3}{|c|}{ Anaemia } \\
\cline { 2 - 5 } & \multicolumn{2}{|c|}{ Anaemic } & \multicolumn{2}{c|}{ Healthy } \\
\cline { 2 - 5 } & Count & $\begin{array}{c}\text { Mean } \\
\text { (millions/cu. } \\
\text { mm) }\end{array}$ & Count & $\begin{array}{c}\text { Mean } \\
\text { (millions/cu. } \\
\text { mm) }\end{array}$ \\
\hline Male & 9 & 3.01 & 15 & 4.75 \\
\hline Female & 20 & 2.81 & 56 & 4.03 \\
\hline
\end{tabular}

\begin{tabular}{|c|c|c|c|c|}
\hline \multirow{2}{*}{ Sex } & \multicolumn{4}{|c|}{ Hb } \\
\cline { 2 - 5 } & \multicolumn{2}{|c|}{ Anaemic } & \multicolumn{2}{c|}{ Healthy } \\
\cline { 2 - 5 } & Count & Mean(g/dL) & Count & Mean (g/dL) \\
\hline Male & 10 & 7.72 & 14 & 14.21 \\
\hline Female & 40 & 7.26 & 36 & 13.51 \\
\hline
\end{tabular}

\begin{tabular}{|c|c|c|c|}
\hline & & Mean \pm S.D. & P VALUE \\
\hline \multirow{2}{*}{ MCV (fL) } & Anaemic $(n=50)$ & $69.62 \pm 3.17$ & \multirow{2}{*}{$\mathrm{P}<0.001$} \\
\hline & Healthy $(n=50)$ & $91.20 \pm 3.67$ & \\
\hline \multirow{2}{*}{$\mathrm{MCH}(\mathrm{pg})$} & Anaemic $(n=50)$ & $26.77 \pm 5.562$ & \multirow{2}{*}{$\mathrm{P}<0.001$} \\
\hline & Healthy $(n=50)$ & $30.50 \pm 2.71$ & \\
\hline \multirow{2}{*}{$\operatorname{MCHC}(\mathrm{g} / \mathrm{dL})$} & Anaemic $(n=50)$ & $38.50 \pm 7.93$ & \multirow{2}{*}{$\mathrm{P}<0.001$} \\
\hline & Healthy $(n=50)$ & $33.50 \pm 3.19$ & \\
\hline \multirow[b]{2}{*}{ RDW } & Anaemic $(n=50)$ & $19.65 \pm 2.88$ & \multirow{2}{*}{$\mathrm{P}<0.001$} \\
\hline & Healthy $(n=50)$ & $13.21 \pm 0.68$ & \\
\hline
\end{tabular}

\begin{tabular}{|c|c|c|c|c|c|}
\hline & Anaemia & N & Mean & S.D. & $\begin{array}{c}\text { P } \\
\text { value }\end{array}$ \\
\hline $\begin{array}{c}\text { Fasting Blood } \\
\text { Sugar }\end{array}$ & Anaemic & 50 & 78.72 & 10.14 & \\
\cline { 1 - 4 } (FBS) (mg/dL) & Healthy & 50 & 81.14 & 7.81 & \multirow{2}{*}{$>0.05$} \\
\cline { 1 - 4 } $\begin{array}{c}\text { Post-Prandial } \\
\text { Blood }\end{array}$ & Anaemic & 50 & 124.68 & 8.96 & \\
\cline { 1 - 4 } $\begin{array}{c}\text { Sugar (PPBS) } \\
\text { (mg/dL) }\end{array}$ & Healthy & 50 & 126.32 & 8.43 & \\
\cline { 1 - 5 } & &
\end{tabular}

Table 5: Fasting, Post-Prandial Blood Sugar and Anaemia

\begin{tabular}{|c|c|c|c|c|c|}
\hline & Anaemia & $\mathbf{N}$ & Mean & S.D & P Value \\
\hline \multirow{2}{*}{ HbA1C (\%) } & Anaemic & 50 & 5.3248 & .32798 & \\
\hline & Healthy & 50 & 5.1440 & .53190 & 0.043 \\
\hline \multicolumn{6}{|c|}{ Table 6: Anaemia and HbA1c } \\
\hline & Anaemia & $\mathbf{N}$ & Mean & S.D & P Value \\
\hline \multirow{2}{*}{$\begin{array}{c}\text { Absolute } \\
\text { HbA1C }\end{array}$} & Anaemic & 50 & .6372 & .09474 & \multirow{2}{*}{$>0.05$} \\
\hline & Healthy & 50 & .7042 & .07299 & \\
\hline
\end{tabular}

\section{DISCUSSION}

The discovery that proteins like Haemoglobin $(\mathrm{Hb})$ were nonenzymatically glycated in vivo depending on the sugar values gave a new dimension to the field of monitoring the glycaemic control of diabetic patients. Apart from routine monitoring of fasting and post-prandial values, glycated haemoglobins gave a good index of glycaemic control over the past few weeks or months.

HbA1c, varyingly called as the glucohaemoglobin, glycated haemoglobin makes the most of the glycated haemoglobin. It has a stable adduct of glucose, which is linked by covalent bonds to the $\mathrm{N}$-terminal valine of the $\beta$ chain. Because life span of erythrocytes in the blood is approximately 120 days, $\mathrm{HbA1c}$ represents the overall picture of the glucose concentration over the preceding 8-12 weeks. The ease of being done at any time of the day with the fasting status of the patient having no bearing on the values measured made HbA1c a vital tool in the diagnosis, monitoring and prognostication of the microvascular complications of diabetes from 1990s. ${ }^{6}$ Later, as HbA1c values were found to be affected by the lifespan and other features of erythrocytes, much debate was started into the validation of $\mathrm{HbA1c}$ in special population with anaemia, haemoglobinopathies, haemolytic conditions and conditions like chronic kidney disease which alter the lifespan of RBCs. ${ }^{7}$ Many studies were conducted analysing the effect of microcytic anaemia on HbA1c measurements. These studies have come up with conflicting results. Some have shown a positive correlation, while some have shown a negative correlation.

Kim et $\mathrm{al}^{8}$ study on the effect of iron deficiency on HbA1c 
distribution among non-diabetic adults of the National Health and Nutrition Examination Survey (NHANES) concluded that the HbA1c were elevated in iron-deficient individuals.

Ford et $\mathrm{al}^{9}$ also evaluated 1999-2002 NHANES data and identified a positive correlation between low $\mathrm{Hb}$ and $\mathrm{HbA1c}$ and an inverse correlation between iron levels and HbA1c. They inferred that caution should be exercised when using HbA1c values near diagnostic cut points in the setting of anaemia. $\mathrm{Hb}$ values were expected to change $\mathrm{HbA1c}$ a value by approximately $0.2 \%(2.2 \mathrm{mmol} / \mathrm{mol})$. This change is especially more noticeable at the two ends of the spectrum of $\mathrm{Hb}$ levels.

In Hardikar et al ${ }^{10}$ study, a comparison between $\mathrm{HbA1c}$ and OGTT determined diabetes rates in Pune Children's Study cohort was done. In this study, people had anaemia of different aetiologies like folate and vitamin B12 deficiency were included. More number of people was diagnosed with diabetes or prediabetes when an HbA1c criterion was used than by the gold standard OGTT. Thus, the author proposed that there was an increased potential for misdiagnosis of diabetes and prediabetes in iron-deficient populations when HbA1c values alone are used. The haematological parameters that were relevant to higher HbA1c levels were erythrocyte microcytosis, low $\mathrm{MCH}$, low $\mathrm{MCHC}$ and high RDW. Also, the results showed that mixed nutrient deficiencies can have various and unpredictable influences on $\mathrm{HbA} 1 \mathrm{c}$ values.

Shanthi.11 and others studied the difference between HbA1c values in 50 non-diabetic individuals with iron deficiency anaemia and non-anaemic healthy controls. HbA1c values were significantly higher in the IDA group when compared with the control group $(\mathrm{P}<0.001)$.

Coban and others'.12 study comprised 100 participants (50 having Iron Deficiency Anaemia (IDA) with 50 healthy controls matched for age and sex. Patients with Iron Deficiency Anaemia (IDA) were given oral supplementation of ferrous sulphate $100 \mathrm{mg}$ a day for 3 months. HbA1c values dropped significantly after iron treatment $(\mathrm{p}<0.001)$. This study suggests that iron deficiency must be corrected before using $\mathrm{HbA1c}$ for making a diagnostic or therapeutic decision.

Sinha et al ${ }^{13}$ came up with a study which contradicted the other results, in that $\mathrm{HbA1c}$ and absolute $\mathrm{HbA1c}$ levels increased after correction of anaemia. This study included administering iron supplementation to 50 participants with iron deficiency anaemia and serial monitoring of the erythrocytic indices, while the erythrocytic indices were measured only once in controls. Mean HbA1c after 2 months $(5.9 \pm 0.6 \%)$ had significantly raised from the baseline $(\mathrm{p}<0.01)$. A significant increase was observed in the absolute HbA1c levels at 2 months after treatment $(0.29 \mathrm{~g} / \mathrm{dL}$ vs. 0.73 $\mathrm{g} / \mathrm{dL}, \mathrm{p}<0.01)$.

Having conflicting results from previous studies, this study was principally conducted to establish the role of microcytic hypochromic anaemia on HbA1c levels in nondiabetic individuals if any. The difference in the mean HbA1c values between anaemic and healthy population was statistically significant ( $\mathrm{P}$ value 0.043 ). This is in concordance with the observation by Shanthi et al, Hardikar et al. They had all observed a modest increase of $\mathrm{HbA1c}$ in anaemic population. They postulated that iron deficiency causes increased glycation leading to spuriously high values of HbA1c. This is different from the observation by Sinha et al and Ford et al who have shown that mean HbA1c is decreased in anaemic population.

Absolute HbA1c values were not significantly different between anaemic and healthy participants. This is in concordance with the observation by Sinha et al. It was the first and only study, which has correlated absolute $\mathrm{HbA1c}$ and anaemia and that has been confirmed by the present study.

\section{CONCLUSION}

\section{Does it make Real Sense for General Population?}

At this juncture, answer will be a definite yes. There is an increase in the number of people with young onset obesity, many among them are menstruating females at risk for iron deficiency anaemia. These people are expected to have high HbA1c values due to obesity related insulin resistance and other conditions.

Thus, a speculated increase due to iron deficiency though modest might shift the HbA1c value from pre-diabetes to diabetes.

\section{Does it Make Real Sense for Diabetics?}

The answer might not be a definite yes, as the expected change is not very high. The following might be the situations where this finding may have a bearing:

1. A search for abnormalities of erythrocyte indices when dealing with discordant glucose and HbA1c values.

2. HbA1c needs to be used with caution in menstruating women at risk for iron deficiency anaemia.

3. If there is an abnormality with erythrocyte indices or anaemia, they need to be corrected before considering using $\mathrm{HbA} 1 \mathrm{c}$ for monitoring diabetes.

\section{Lacunae and Future Research Prospects}

Though there are hypothesis for spuriously elevated HbA1c levels like iron deficiency augmenting glycation, reduced lifespan of erythrocytes, the exact mechanism for the alteration in the value of $\mathrm{HbA} 1 \mathrm{c}$ is not known. Also the effect of other types of anaemia and effect of mixed nutritional deficiencies needs to be determined.

\section{LIMITATIONS OF THE STUDY}

- The sample size was small.

- Majority of the individuals involved in the study was younger population. A study involving equal distribution of participants in various age groups would have thrown light upon other factors operating in the elderly individuals.

- A confirmatory test for iron deficiency like serum ferritin was not applied in this study. A broad label of microcytic hypochromic anaemia is used.

- The study was a case control study. No effort was made at correcting anaemia and henceforth the changes in the trend were not observed.

- Further studies involving a larger population where the limitations of this study are duly taken into consideration are needed.

\section{REFERENCES}

1. WHO/ facts and figures about diabetes. http://www.who. int/diabetes/facts/en/

2. INDIA- Diabetes Capital of the World. http://www.neemanmedical.com/sites/default/files/files/India\%2020Diabetic\%20Capital\%20of\%20World.pdf 
3. Hinzmann R, Schlaeger C, Tran CT. What do we need beyond haemoglobin A1c to get the complete picture of glycaemia in people with diabetes? International Journal of Medical Science 2012;9(8):665-81.

4. Bruno de B, Lean EM, Egli I, et al. Worldwide prevalence of anaemia 1993-2005. WHO Global Database On Anaemia 2008:pgs40.

5. Lichtman MA, Williams WJ. Williams haematology. 7th edn. Vol 487. McGraw-Hill Companies 2006:pgs2297.

6. DCCT and EDIC: The Diabetes Control and Complications Trial and Follow-up Study-19831993.http://www.niddk. nih.gov/

7. Elizabeta.topic@gmail.com; Guidelines and recommendations for testing in diagnosis of diabetes mellitus: The role of HbA1c. Biochemia Medica 2014;24 (Suppl 1):S17-20.

8. Kim C, Bullard KMK, Herman WH, et al. Association between iron deficiency and HbA1c levels among adults without diabetes in the national health and nutrition examination survey, 1999-2006. Diabetes Care 2010; 33(4):780-5.
9. Ford ES, Cowie CC, Li C, et al. Iron-deficiency anaemia, non-iron-deficiency anaemia and HbA1c among adults in the US. J Diabetes 2011;3(1):67-73.

10. Hardikar PS, Joshi SM, Bhat DS, et al. Spuriously high prevalence of prediabetes diagnosed by HbA1c in young Indians partly explained by haematological factors and iron deficiency anaemia. Diabetes Care 2012;35(4):797802.

11. Shanthi B, Revathy C, Devi AJM, et al. Effect of iron deficiency on glycation of haemoglobin in non-diabetics. Journal of Clinical and Diagnostic Research 2013;7(1):15-7.

12. Coban E, Ozdogan M, Timuragaglu A. Effect of iron deficiency anaemia on the levels of haemoglobin A1c in non-diabetic patients. Acta Haematol 2004;112(3): 126-8.

13. Sinha N, Mishra TK, Singh $\mathrm{T}$, et al. Effect of iron deficiency anaemia on haemoglobin A1c levels. Annals of Laboratory Medicine 2012;32(1):17-22. 